\title{
Sex Differences In The Association Between Hemoglobin A1c And Cerebral White Matter Lesions In The General Japanese Population
}

Honghao Li

Shandong Provincial Hospital Affiliated to Shandong First Medical University

Jing Yu

Shandong Medical College

Shougang Guo ( $\nabla$ guoshougang1124@163.com )

Shandong Provincial Hospital Affiliated to Shandong First Medical University

\section{Research Article}

Keywords: hemoglobin A1c, cerebral white matter lesions, association, generalized additive model, interaction effect

Posted Date: June 9th, 2021

DOI: https://doi.org/10.21203/rs.3.rs-558372/v1

License: (a) (1) This work is licensed under a Creative Commons Attribution 4.0 International License. Read Full License 


\section{Abstract}

The influence of diabetes and associated sex differences on cerebral white matter lesions (WMLs) is unclear. We used data from a cross-sectional study uploaded to the DATADRYAD website by Shinkawa et al. to investigate differences in the association between hemoglobin $\mathrm{A} 1 \mathrm{c}(\mathrm{HbA} 1 \mathrm{c})$ levels and cerebral WMLs between men and women. The average age of all participants was $56.4 \pm 11.5 y e a r s$ old, and approximately $51.89 \%$ of them were men. A linear relationship between $\mathrm{HbA1c}$ and cerebral WMLs was detected in men. Fully adjusted binary logistic regression showed no association of $\mathrm{HbA} 1 \mathrm{c}$ with cerebral WMLs in men. A nonlinear relationship between HbA1c and cerebral WMLs was detected in women, whose cutoff point was $5.6 \%$. The effect sizes and confidence intervals of the left and right sides of the inflection point were $\mathrm{OR}=0.21(95 \% \mathrm{Cl} 0.06,0.69, \mathrm{P}=0.0098)$ and $\mathrm{OR}=3.5(95 \% \mathrm{Cl} 1.50,8.15, \mathrm{P}=0.0037)$, respectively. In the higher $\mathrm{HbA1c}$ group, further subgroup analysis showed a stronger association between $\mathrm{HbA} 1 \mathrm{c}$ and cerebral WMLs in women $(\mathrm{OR}=3.83,95 \% \mathrm{Cl} 1.68,8.72 \mathrm{P}=0.0014)$ than in men $(\mathrm{OR}=1.02,95 \% \mathrm{Cl} 0.76,1.36 \mathrm{P}=0.8986)$ ( $\mathrm{P}$ for interaction with sex was 0.0004$)$. A stronger effect of $\mathrm{HbA} 1 \mathrm{c}$ on the risk of cerebral WMLs in women than in men was found in the higher HbA1c group.

\section{Introduction}

Rapid population aging combined with sedentary habits has made type 2 diabetes one of the largest public health problems worldwide ${ }^{1,2}$. Recent studies have demonstrated that in addition to diabetes, prediabetes can damage small and large blood vessels and lead to complications such as neuropathy, nephropathy and macrovascular diseases ${ }^{3-6}$. More recent investigations have shown considerable sex differences associated with diabetes risk factors, hormonal effects on glucose, and diabetic vascular and nonvascular outcomes ${ }^{7-9}$. It has now been well established by a variety of studies that a higher HbA1c level, as a biomarker of long-term glycemic control, is an independent risk factor for diabetes complications ${ }^{10-12}$. Cerebral WMLs are mainly chronic ischemic lesions caused by small vessel diseases, which show white matter hyperintensities (WMHs) on T2-weighted or fluid-attenuated inversion recovery (FLAIR) images in magnetic resonance imaging (MRI) and are associated with cognitive impairment, gait dysfunction and focal neurological signs ${ }^{13}$. Many factors have been found to be related to cerebral WMLs, such as age, hypertension, dyslipidemia, smoking and various biomarkers of vascular disease ${ }^{14}$. Although DM is well known as a vascular risk factor, the relationship between DM and cerebral WMLs is still controversial ${ }^{15-18}$. Prediabetes was also shown to be associated with brain structural abnormalities ${ }^{19}$. HbA1c, which reflects a measure of glycemia during the previous $2-3$ months, is a biomarker for long-term glycemic control and is also indicative of prediabetes. Previous studies have shown a significant association between $\mathrm{HbA1}$ c and cerebral WMLs ${ }^{20-22}$. However, such conclusions were not confirmed by another study conducted in a larger cohort of patients ${ }^{23}$. In addition, the sex differences in the relationship between $\mathrm{HbA} 1 \mathrm{c}$ and cerebral WMLs have still not been illuminated in previous studies. 
In this study, a secondary data analysis was performed using existing data from a published paper ${ }^{24}$. In the secondary analysis, the independent variable and dependent variable were $\mathrm{HbA} 1 \mathrm{c}$ level and cerebral WMLs, respectively. Other covariates are consistent with those in the original. This analysis sought to investigate whether sex differences exist in the association between $\mathrm{HbA1c}$ levels and the incident risk of cerebral WMLs in the general population.

\section{Results}

\section{Baseline characteristics of participants}

A total of 1904 participants were included in the final data analysis, with 988 men and 916 women classified into two groups (lower HbA1c group and higher HbA1c group) according to the clinical cutoff point of $\mathrm{HbA1c}$. The baseline characteristics of these groups are reported in Table 1. In general, the average age of the 1904 participants was $56.4 \pm 11.5$ years old, and approximately $51.89 \%$ of them were male. No statistically significant differences were detected in LDL, HbA1c, or medication to reduce blood sugar or insulin injection between men and women in the lower HbA1c group (all p values > 0.05 ). Women had higher values in age and HDL and were more likely to exhibit the following values than men in the lower HbA1c group: metabolic syndrome (no), smoking habit (no), medication to reduce blood pressure (no), medication to reduce the level of cholesterol (yes), amount of drinking per day $(<180 \mathrm{ml})$, drinking habit (rarely), plaque number ( 0 ) and cerebral WMLs (yes). The opposite patterns were observed in LH, TG, BS, SBP, DBP, BMI, PS, metabolic syndrome (reserve and yes), smoking habit (yes), medication to reduce blood pressure (yes), medication to reduce the level of cholesterol (no), amount of drinking per day $(>180 \mathrm{ml})$, plaque number $(\mathrm{n}>=1)$ and cerebral WMLs (no) in the lower HbA1c group. No statistically significant differences were detected in SBP or medication to reduce the level of cholesterol between men and women in the higher $\mathrm{HbA1c}$ group. Women had higher values of age, $\mathrm{LDL}$, and $\mathrm{HDL}$ and were more likely to have metabolic syndrome (no), smoking habit (no), medication to reduce blood pressure (no), medication to reduce blood sugar or insulin injection (no), amount of drinking per day $(<180 \mathrm{ml})$ and drinking habit (rarely) and plaque number (0) and cerebral WMLs (yes) in the higher $\mathrm{HbA1c}$ group. The opposite patterns were observed in LH, TG, HbA1c, BS, DBP, BMI, PS, metabolic syndrome (reserve and

yes), smoking habit (yes), medication to reduce blood pressure (yes), medication to reduce blood sugar or insulin injection (yes), amount of drinking per day (> $180 \mathrm{ml}$ ), drinking habit (sometimes and everyday), plaque number $(n>=1)$ and cerebral WMLs (no). 
Table 1

Baseline characteristics and level of cerebral white matter lesion risk factors by sex in the general Japanese population.

\begin{tabular}{|c|c|c|c|c|c|c|}
\hline \multicolumn{4}{|c|}{ HbA1c $<5.7(\%)$} & \multicolumn{3}{|l|}{$\mathrm{HbA} 1 \mathrm{c}>=5.7(\%)$} \\
\hline \multirow{2}{*}{$\begin{array}{l}\text { 408) } \\
\begin{array}{l}\text { Age } \\
\text { (years) }\end{array}\end{array}$} & \multirow{2}{*}{$\begin{array}{l}\text { Men }(n=527) \\
\text { P value } \\
50.86 \pm \\
11.78\end{array}$} & \multicolumn{2}{|c|}{ Women $(\mathrm{n}=$} & \multirow{2}{*}{$\begin{array}{l}\operatorname{Men}\left(n=\begin{array}{l}461) \\
\text { P value }\end{array}\right. \\
59.03 \pm 10.28\end{array}$} & \multicolumn{2}{|c|}{ Women $(n=508)$} \\
\hline & & $\begin{array}{l}53.45 \pm \\
11.38\end{array}$ & 0.002 & & $61.86 \pm 8.72$ & $<0.001$ \\
\hline $\begin{array}{l}\text { LDL } \\
(\mathrm{mg} / \mathrm{dl})\end{array}$ & $\begin{array}{l}115.95 \pm \\
30.70\end{array}$ & $\begin{array}{l}119.29 \pm \\
28.56\end{array}$ & 0.098 & $121.23 \pm 30.87$ & $126.90 \pm 30.25$ & 0.007 \\
\hline $\begin{array}{l}\mathrm{HDL} \\
(\mathrm{mg} / \mathrm{dl})\end{array}$ & $\begin{array}{l}57.31 \pm \\
14.43\end{array}$ & $\begin{array}{l}69.38 \pm \\
15.41\end{array}$ & $\begin{array}{l}<.001 \\
0.00\end{array}$ & $53.96 \pm 12.90$ & $64.95 \pm 14.17$ & $<0.001$ \\
\hline LH & $2.16 \pm 0.80$ & $1.81 \pm 0.60$ & $\begin{array}{l}<.001 \\
0.001\end{array}$ & $2.37 \pm 0.82$ & $2.05 \pm 0.68$ & $<0.001$ \\
\hline $\begin{array}{l}\text { TG } \\
(\mathrm{mg} / \mathrm{dl})\end{array}$ & $\begin{array}{l}125.50 \pm \\
145.38\end{array}$ & $\begin{array}{l}80.14 \pm \\
45.66\end{array}$ & $\begin{array}{l}<.001 \\
0.01\end{array}$ & $139.41 \pm 97.24$ & $98.04 \pm 57.60$ & $<0.001$ \\
\hline HbA1c (\%) & $5.40 \pm 0.19$ & $5.40 \pm 0.18$ & 0.944 & $6.24 \pm 0.86$ & $6.01 \pm 0.48$ & 0.002 \\
\hline BS (mg/dl) & $99.60 \pm 8.01$ & $\begin{array}{l}94.95 \pm \\
6.87\end{array}$ & $\begin{array}{l}<.001 \\
0.01\end{array}$ & $116.80 \pm 27.06$ & $104.53 \pm 15.56$ & $<0.001$ \\
\hline $\begin{array}{l}\text { SBP } \\
(\mathrm{mmHg})\end{array}$ & $\begin{array}{l}123.32 \pm \\
15.84\end{array}$ & $\begin{array}{l}118.65 \pm \\
19.10\end{array}$ & $<.001$ & $127.50 \pm 18.15$ & $125.36 \pm 19.70$ & 0.058 \\
\hline $\begin{array}{l}\text { DBP } \\
(\mathrm{mmHg})\end{array}$ & $\begin{array}{l}76.05 \pm \\
11.38\end{array}$ & $\begin{array}{l}70.38 \pm \\
12.82\end{array}$ & $\begin{array}{l}<.001 \\
0.00\end{array}$ & $76.07 \pm 11.83$ & $72.40 \pm 11.94$ & $<0.001$ \\
\hline BMI & $23.40 \pm 2.85$ & $\begin{array}{l}21.52 \pm \\
2.90\end{array}$ & $<.001$ & $24.82 \pm 3.51$ & $22.68 \pm 3.44$ & $<0.001$ \\
\hline PS & $1.01 \pm 1.94$ & $0.50 \pm 1.24$ & $\begin{array}{l}<.001 \\
0 .\end{array}$ & $1.87 \pm 2.49$ & $0.92 \pm 1.74$ & $<0.001$ \\
\hline Met-syn & & & $<.001$ & & & $<0.001$ \\
\hline no & $\begin{array}{l}387 \\
(73.43 \%)\end{array}$ & $\begin{array}{l}387 \\
(94.85 \%)\end{array}$ & & 220 (47.72\%) & 435 (85.63\%) & \\
\hline reserve & $85(16.13 \%)$ & $11(2.70 \%)$ & & $67(14.53 \%)$ & $33(6.50 \%)$ & \\
\hline yes & 55 (10.44\%) & $10(2.45 \%)$ & & 174 (37.74\%) & $40(7.87 \%)$ & \\
\hline
\end{tabular}

Abbreviations: LDL, low-density lipoprotein; HDL, high-density lipoprotein; $L H$, quotient of $L D L$ and HDL; TG, triglyceride; BS, blood glucose level; SBP, systolic blood pressure; DBP, diastolic blood pressure; BMI, body mass index; PS, carotid plaque score; Met-syn, metabolic syndrome; Med-bp, medication to reduce blood pressure; Med-sugar, medication to reduce blood sugar or insulin injection; Med-cho, medication to reduce the level of cholesterol; Drink-V, amount of drinking per day; WMLs, white matter lesions. 


\begin{tabular}{|c|c|c|c|c|c|c|}
\hline \multicolumn{3}{|c|}{$\mathrm{HbA1c}<5.7(\%)$} & \multicolumn{3}{|c|}{$\mathrm{HbA} 1 \mathrm{c}>=5.7(\%)$} & \multirow[b]{2}{*}{$<0.001$} \\
\hline Smoking & & & $<.001$ & & & \\
\hline no & $\begin{array}{l}365 \\
(69.26 \%)\end{array}$ & $\begin{array}{l}381 \\
(93.38 \%)\end{array}$ & & $330(71.58 \%)$ & 492 (96.85\%) & \\
\hline yes & $\begin{array}{l}162 \\
(30.74 \%)\end{array}$ & $27(6.62 \%)$ & & $131(28.42 \%)$ & $16(3.15 \%)$ & \\
\hline Med-bp & & & 0.002 & & & 0.001 \\
\hline no & $\begin{array}{l}417 \\
(79.13 \%)\end{array}$ & $\begin{array}{l}354 \\
(86.76 \%)\end{array}$ & & $296(64.21 \%)$ & 375 (73.82\%) & \\
\hline yes & $\begin{array}{l}110 \\
(20.87 \%)\end{array}$ & $\begin{array}{l}54 \\
(13.24 \%)\end{array}$ & & 165 (35.79\%) & $133(26.18 \%)$ & \\
\hline Med-sugar & & & 0.213 & & & $<0.001$ \\
\hline no & $\begin{array}{l}525 \\
(99.62 \%)\end{array}$ & $\begin{array}{l}408 \\
(100.00 \%)\end{array}$ & & 359 (77.87\%) & $473(93.11 \%)$ & \\
\hline yes & $2(0.38 \%)$ & $0(0.00 \%)$ & & $102(22.13 \%)$ & 35 (6.89\%) & \\
\hline Med-cho & & & 0.013 & & & 0.990 \\
\hline no & $\begin{array}{l}497 \\
(94.31 \%)\end{array}$ & $\begin{array}{l}367 \\
(89.95 \%)\end{array}$ & & 345 (74.84\%) & $380(74.80 \%)$ & \\
\hline yes & $30(5.69 \%)$ & $\begin{array}{l}41 \\
(10.05 \%)\end{array}$ & & $116(25.16 \%)$ & $128(25.20 \%)$ & \\
\hline Drink-V & & & $<.001$ & & & $<0.001$ \\
\hline 1 & $\begin{array}{l}204 \\
(38.71 \%)\end{array}$ & $\begin{array}{l}345 \\
(84.56 \%)\end{array}$ & & 224 (48.59\%) & $451(88.78 \%)$ & \\
\hline 2 & $\begin{array}{l}197 \\
(37.38 \%)\end{array}$ & $\begin{array}{l}50 \\
(12.25 \%)\end{array}$ & & $171(37.09 \%)$ & $49(9.65 \%)$ & \\
\hline 3 & $\begin{array}{l}126 \\
(23.91 \%)\end{array}$ & $13(3.19 \%)$ & & $66(14.32 \%)$ & $8(1.57 \%)$ & \\
\hline Drinking & & & $<.001$ & & & $<0.001$ \\
\hline
\end{tabular}

Abbreviations: $L D L$, low-density lipoprotein; $H D L$, high-density lipoprotein; $L H$, quotient of $L D L$ and HDL; TG, triglyceride; BS, blood glucose level; SBP, systolic blood pressure; DBP, diastolic blood pressure; BMI, body mass index; PS, carotid plaque score; Met-syn, metabolic syndrome; Med-bp, medication to reduce blood pressure; Med-sugar, medication to reduce blood sugar or insulin injection; Med-cho, medication to reduce the level of cholesterol; Drink-V, amount of drinking per day; WMLs, white matter lesions. 


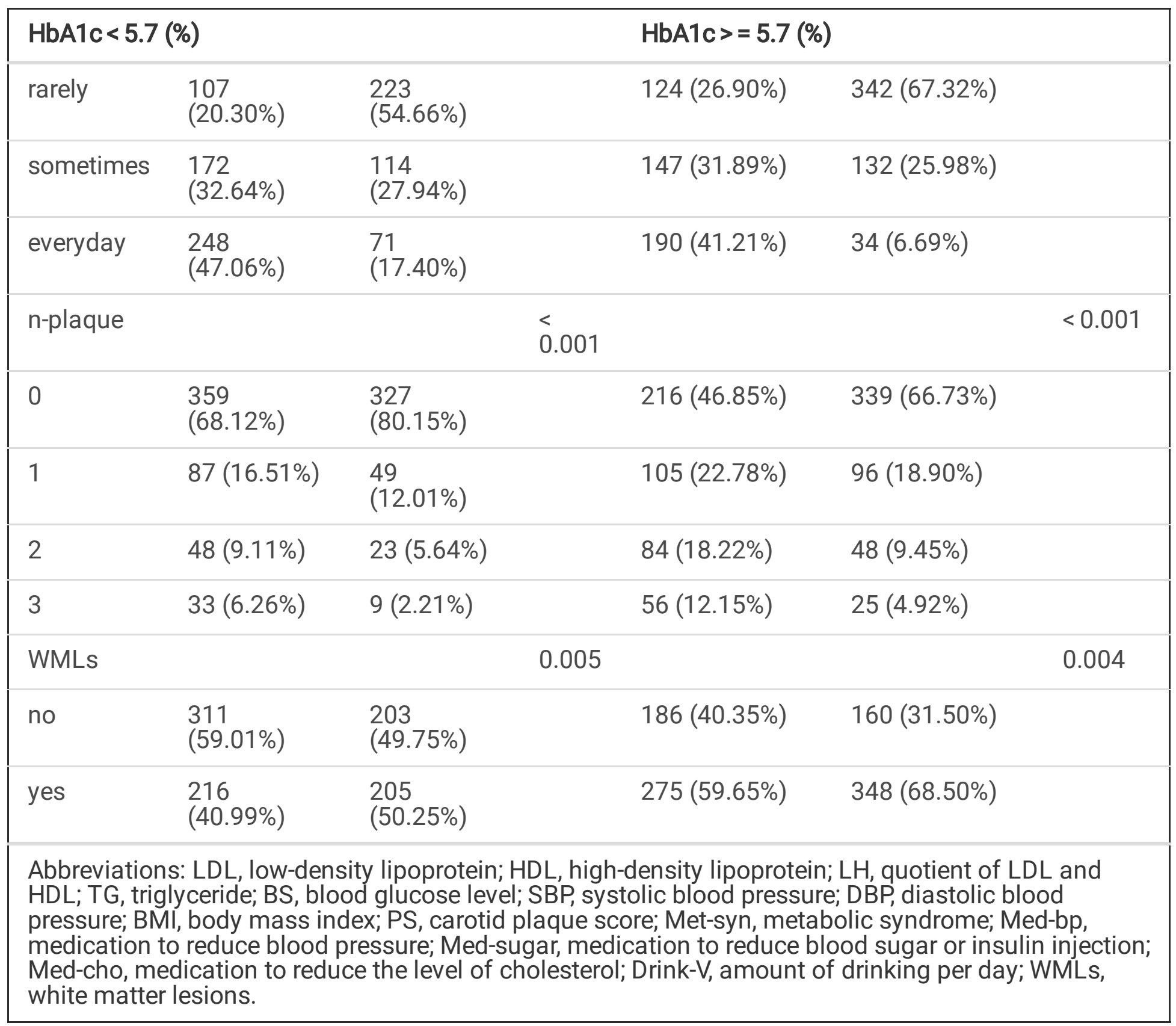

\section{Univariate analysis}

We listed the results of univariate analyses, adjusting for age, for men and women in Table 2. By univariate binary logistic regression adjusting for age, we found that $L D L, H D L, L H, T G, H b A 1 c, B S$, smoking habits, amount of drinking per day and plaque number $(n=1, n=2, n>2)$ were not associated with cerebral WMLs in men. We also found that PS odds ratio $(O R)=1.09(95 \% \mathrm{Cl} 1.01,1.18 \mathrm{P}=0.0365)$, SBP OR $=1.01(95 \% \mathrm{Cl} 1.00,1.02 \mathrm{P}=0.0392), \mathrm{DBP} O \mathrm{OR}=1.02(95 \% \mathrm{Cl} 1.01,1.03 \mathrm{P}=0.0013), \mathrm{BMI} \mathrm{OR}=1.05$ $(95 \% \mathrm{Cl} 1.00,1.10 \mathrm{P}=0.0358)$, metabolic syndrome (reserve) $\mathrm{OR}=1.53(95 \% \mathrm{Cl} 1.00,2.32 \mathrm{P}=0.0475)$, metabolic syndrome (yes) $\mathrm{OR}=1.59(95 \% \mathrm{Cl} 1.11,2.28 \mathrm{P}=0.0113)$, medication to reduce blood pressure (yes) $\mathrm{OR}=1.74(95 \% \mathrm{Cl} 1.23,2.45 \mathrm{P}=0.0017)$, medication to reduce sugar or insulin injection (yes) $\mathrm{OR}=$ $1.70(95 \% \mathrm{Cl} 1.02,2.85 \mathrm{P}=0.0425)$, medication to reduce the level of cholesterol (yes) $\mathrm{OR}=1.61(95 \% \mathrm{Cl}$ $1.06,2.45 \mathrm{P}=0.0271)$, drinking habit (sometimes) $\mathrm{OR}=1.79(95 \% \mathrm{Cl} 1.19,2.71 \mathrm{P}=0.0054)$, and drinking habit (every day) $\mathrm{OR}=1.51(95 \% \mathrm{Cl} 1.03,2.22 \mathrm{P}=0.0355)$ were positively correlated with cerebral WMLs in 
men. By univariate binary logistic regression adjusting for age, we found that $L D L, L H, T G, H b A 1 c, B S$, $\mathrm{BMI}$, metabolic syndrome (reserve or yes), smoking habit, medication to reduce sugar or insulin injection, medication to reduce the level of cholesterol, drinking habit, plaque number $(n=1, n=2, n>2)$ and amount of drinking per day $(180-360 \mathrm{ml})$ were not associated with cerebral WMLs in women. We also found that the amount of drinking per day $(>360 \mathrm{ml}) \mathrm{OR}=0.14(95 \% \mathrm{Cl} 0.04,0.51 \mathrm{P}=0.0030)$ was negatively associated with cerebral WMLs in women. In contrast, univariate analysis showed that PS OR $=1.20(95 \% \mathrm{Cl} 1.05,1.38 \mathrm{P}=0.0093), \mathrm{HDL} \mathrm{OR}=1.01(95 \% \mathrm{Cl} 1.00,1.02 \mathrm{P}=0.0491), \mathrm{SBP} \mathrm{OR}=1.01(95 \% \mathrm{Cl}$ $1.00,1.02 \mathrm{P}=0.0136), \mathrm{DBP} O \mathrm{R}=1.02(95 \% \mathrm{Cl} 1.01,1.03 \mathrm{P}=0.0007)$, medication to reduce blood pressure (yes) $\mathrm{OR}=1.91(95 \% \mathrm{Cl} 1.23,2.98 \mathrm{P}=0.0041)$, and plaque number $(\mathrm{n}>2) \mathrm{OR}=8.86(95 \% \mathrm{Cl} 1.18,66.42 \mathrm{P}=$ 0.0338 ) were positively associated with cerebral WMLs in women.

Table 2 The results of the univariate analysis, adjusting for age, relationship between $\mathrm{HbA} 1 \mathrm{c}$ and cerebral WMLs

Crude association of cerebral WMLs with risk factors and characteristics adjusting for age. 


\begin{tabular}{|c|c|c|c|}
\hline & Men & Women & Total \\
\hline PS & $1.09(1.01,1.18) 0.0365$ & $1.20(1.05,1.38) 0.0093$ & $1.12(1.05,1.20) 0.0010$ \\
\hline LDL (mg/dl) & $1.00(1.00,1.01) 0.5653$ & $1.00(1.00,1.01) 0.6444$ & $1.00(1.00,1.00) 0.5939$ \\
\hline $\mathrm{HDL}(\mathrm{mg} / \mathrm{dl})$ & $1.01(0.99,1.02) 0.3316$ & $1.01(1.00,1.02) 0.0491$ & $1.01(1.00,1.02) 0.0291$ \\
\hline LH & $1.00(0.83,1.21) 0.9790$ & $0.95(0.76,1.20) 0.6824$ & $0.97(0.84,1.12) 0.6633$ \\
\hline TG (mg/dl) & $1.00(1.00,1.00) 0.6516$ & $1.00(1.00,1.00) 0.5256$ & $1.00(1.00,1.00) 0.9972$ \\
\hline HbA1c (\%) & $1.10(0.91,1.34) 0.3133$ & $1.32(0.90,1.93) 0.1576$ & $1.14(0.96,1.35) 0.1306$ \\
\hline BS (mg/dl) & $1.00(1.00,1.01) 0.1744$ & $1.00(0.99,1.01) 0.7592$ & $1.00(1.00,1.01) 0.1902$ \\
\hline SBP (mmHg) & $1.01(1.00,1.02) 0.0392$ & $1.01(1.00,1.02) 0.0136$ & $1.01(1.00,1.02) 0.0018$ \\
\hline DBP (mmHg) & $1.02(1.01,1.03) 0.0013$ & $1.02(1.01,1.03) 0.0007$ & $1.02(1.01,1.03)<0.0001$ \\
\hline BMI & $1.05(1.00,1.10) 0.0358$ & $1.01(0.96,1.06) 0.6710$ & $1.03(1.00,1.06) 0.0904$ \\
\hline \multicolumn{4}{|l|}{ Met-syn } \\
\hline no & 1.0 & 1.0 & 1.0 \\
\hline reserve & $1.53(1.00,2.32) 0.0475$ & $2.30(1.00,5.32) 0.0505$ & $1.64(1.14,2.36) 0.0082$ \\
\hline yes & $1.59(1.11,2.28) 0.0113$ & $1.44(0.69,3.02) 0.3282$ & $1.59(1.15,2.19) 0.0047$ \\
\hline \multicolumn{4}{|l|}{ Smoking } \\
\hline no & 1.0 & 1.0 & 1.0 \\
\hline yes & $0.97(0.70,1.35) 0.8711$ & $0.61(0.30,1.22) 0.1616$ & $0.89(0.66,1.18) 0.4132$ \\
\hline \multicolumn{4}{|l|}{ Med-bp } \\
\hline no & 1.0 & 1.0 & 1.0 \\
\hline yes & $1.74(1.23,2.45) 0.0017$ & $1.91(1.23,2.98) 0.0041$ & $1.81(1.38,2.37)<0.0001$ \\
\hline \multicolumn{4}{|l|}{ Med-sugar } \\
\hline no & 1.0 & 1.0 & 1.0 \\
\hline yes & $1.70(1.02,2.85) 0.0425$ & $1.77(0.66,4.75) 0.2566$ & $1.73(1.10,2.73) 0.0171$ \\
\hline \multicolumn{4}{|l|}{ Med-cho } \\
\hline no & 1.0 & 1.0 & 1.0 \\
\hline yes & $1.61(1.06,2.45) 0.0271$ & $1.29(0.84,1.99) 0.2511$ & $1.42(1.05,1.92) 0.0228$ \\
\hline \multicolumn{4}{|l|}{ Drink-V } \\
\hline 1 & 1.0 & 1.0 & 1.0 \\
\hline
\end{tabular}




\begin{tabular}{|c|c|c|c|}
\hline 2 & $1.11(0.80,1.55) 0.5356$ & $0.91(0.57,1.45) 0.6813$ & $1.00(0.77,1.31) 0.9942$ \\
\hline 3 & $1.32(0.88,1.98) 0.1743$ & $0.14(0.04,0.51) 0.0030$ & $0.99(0.69,1.42) 0.9511$ \\
\hline \multicolumn{4}{|l|}{ Drinking habit } \\
\hline rarely & 1.0 & 1.0 & 1.0 \\
\hline sometimes & $1.79(1.19,2.71) 0.0054$ & $0.97(0.69,1.38) 0.8836$ & $1.24(0.95,1.62) 0.1111$ \\
\hline every day & $1.51(1.03,2.22) 0.0355$ & $0.71(0.44,1.14) 0.1572$ & $1.07(0.81,1.43) 0.6154$ \\
\hline \multicolumn{4}{|l|}{ n-plaque } \\
\hline 0 & 1.0 & 1.0 & 1.0 \\
\hline 1 & $1.45(0.99,2.12) 0.0595$ & $0.88(0.58,1.34) 0.5501$ & $1.17(0.88,1.56) 0.2777$ \\
\hline 2 & $1.46(0.91,2.32) 0.1140$ & $1.54(0.82,2.91) 0.1818$ & $1.48(1.02,2.15) 0.0375$ \\
\hline 3 & $1.79(0.99,3.25) 0.0539$ & $8.86(1.18,66.42) 0.0338$ & $2.21(1.29,3.78) 0.0038$ \\
\hline
\end{tabular}

Abbreviations: LDL, low-density lipoprotein; HDL, high-density lipoprotein; $L H$, quotient of $L D L$ and $H D L$; TG, triglyceride; BS, blood glucose level; SBP, systolic blood pressure; DBP, diastolic blood pressure; BMI, body mass index; PS, carotid plaque score; Met-syn, metabolic syndrome; Med-bp, medication to reduce blood pressure; Med-sugar, medication to reduce blood sugar or insulin injection; Med-cho, medication to reduce the level of cholesterol; Drink-V, amount of drinking per day.

\section{Results of unadjusted and adjusted binary logistic regression}

\section{The results of nonlinearity of HbA1c and cerebral white matter lesions for men and women}

In the present study, we analyzed the nonlinear relationship between $\mathrm{HbA} 1 \mathrm{c}$ and cerebral WMLs for men and women (Fig. 1a and Fig. 1b). The smooth curve and the result of the generalized additive model showed a linear association of $\mathrm{HbA} 1 \mathrm{c}$ with cerebral WMLs in men after adjusting for age, PS, LDL, HDL, TG, BS, SBP, DBP, BMI, metabolic syndrome, medication to reduce blood pressure, medication to reduce blood sugar or insulin injection, medication to reduce the level of cholesterol, drinking habit and plaque number. In this study, we constructed two models to analyze the independent effects of HbA1c on cerebral WMLs (univariate and multivariate binary logistic regression). Binary logistic regression showed that there was no association of HbA1c with cerebral WMLs in men. The effect sizes (OR) and 95\% confidence intervals are listed in Table 3 . In the minimally adjusted model (model 1), the model-based effect size can be explained as a one-unit difference in HbA1c level associated with risk of WMLs. The smooth curve and the result of the generalized additive model showed that the relationship between $\mathrm{HbA1c}$ and cerebral WMLs was nonlinear in women after adjusting for age, PS, LDL, HDL, TG, BS, SBP, DBP, BMI, metabolic syndrome, medication to reduce blood pressure, medication to reduce blood sugar or insulin injection, medication to reduce the level of cholesterol, drinking habit and plaque number. We used both binary logistic regression and two-piecewise binary logistic regression to fit the association and select the best fit model based on $\mathrm{P}$ for the log likelihood ratio test. 
Table 3

Multiple regression analysis of the relationship between $\mathrm{HbA} 1 \mathrm{c}$ and cerebral WMLs in men

\begin{tabular}{|c|c|c|}
\hline Variable & Minimally adjusted model (OR, 95\% Cl, P) & Fully adjusted model (OR, 95\%Cl, P) \\
\hline $\mathrm{HbA1c}(\%)$ & $1.10(0.91,1.34) 0.3133$ & $0.87(0.59,1.29) 0.4998$ \\
\hline
\end{tabular}

Minimally adjusted model: we adjusted for age.

Fully adjusted model: we adjusted for age, HDL, LDL, TG, DBP, SBP, BMI, BS, PS, drinking habit, metabolic syndrome, medication to reduce blood pressure, medication to reduce blood sugar or insulin injection, medication to reduce cholesterol levels, and n-plaque.

Because the $P$ for the log likelihood ratio test was less than 0.05 , we chose two-piecewise binary logistic regression for fitting the association between HbA1c and cerebral WMLs in women because it can accurately represent the relationship. Using a two-piecewise binary logistic regression and recursive algorithm, we calculated that the inflection point was $5.6 \%$. On the left side of the inflection point, the effect size and $95 \% \mathrm{Cl}$ were $0.21(0.06,0.69), P=0.0098$. On the right side of the inflection point, the effect size and $95 \% \mathrm{Cl}$ were $3.5(1.50,8.15)(P=0.0037)($ Table 4$)$.

Table 4 The results of the two-piecewise linear regression model in women

For exposure: HbA1c

For outcome: WMLs

\begin{tabular}{|ll|}
\hline Model I & \\
\hline one linear regression coefficient & $1.41(0.83,2.37) 0.2018$ \\
\hline Model II & 5.6 \\
\hline Inflection point $(\mathrm{K})$ & $0.21(0.06,0.69) 0.0098$ \\
\hline$<$ K-segment regression coefficient 1 & $3.5(1.50,8.15) 0.0037$ \\
\hline$>$ K-segment regression coefficient 2 & $16.77(3.35,84.01) 0.0006$ \\
\hline The difference between regression coefficient 2 and 1 & $0.23(0.01,0.44)$ \\
\hline Predicted value of Y at the inflection point & $<0.001$ \\
\hline Log Likelihood Ratio Tests & \\
\hline
\end{tabular}

Effect: cerebral WMLs, Cause: HbA1c

We adjusted for age, HDL, LDL, TGs, DBP, SBP, BMI, BS, PS, drinking habits, metabolic syndrome, medication to reduce blood pressure, medication to reduce blood sugar or insulin injection, and medication to reduce cholesterol and n-plaque levels. 
We used sex as the stratification variable to observe the trend of effect sizes in this variable (Table 5). We noted that there was an interaction between sex and $\mathrm{HbA} 1 \mathrm{c}$ based on our a priori specification in the higher $\mathrm{HbA} 1 \mathrm{c}$ group $(\mathrm{HbA} 1 \mathrm{c}>=5.7 \mathrm{mmol} / \mathrm{L})(\mathrm{P}$ values for interaction $<0.05)$. In this study, a stronger association was detected in women $(\mathrm{OR}=3.8395 \% \mathrm{Cl} 1.68,8.72, \mathrm{P}=0.0014)$ than in men $(\mathrm{OR}=1.02$ $95 \% \mathrm{Cl} 0.76,1.36, \mathrm{P}=0.8986)$ in the higher $\mathrm{HbA} 1 \mathrm{c}$ group. 
Table 5

Effect size of $\mathrm{HbA} 1 \mathrm{c}$ on cerebral white matter lesions in subgroups stratified by sex and $\mathrm{HbA} 1 \mathrm{c}$

\begin{tabular}{|c|c|c|c|}
\hline Model & Men & Women & P interaction \\
\hline \multicolumn{4}{|c|}{ HBA1C < 5.7\% } \\
\hline Crude & $1.77(0.68,4.56) 0.2392$ & $2.46(0.80,7.56) 0.1171$ & 0.6606 \\
\hline Model I & $1.24(0.40,3.84) 0.7126$ & $0.18(0.05,0.67) 0.0109$ & 0.0283 \\
\hline Model I* & $1.23(0.38,3.94) 0.7295$ & $0.25(0.06,0.97) 0.0448$ & 0.0799 \\
\hline Model II & $1.36(0.45,4.05) 0.5853$ & $1.13(0.33,3.85) 0.8479$ & 0.8228 \\
\hline Model II* & $1.69(0.56,5.13) 0.3515$ & $0.85(0.24,3.05) 0.8086$ & 0.4259 \\
\hline \multicolumn{4}{|c|}{ HBA1C > = 5.7\% } \\
\hline Crude & $1.10(0.88,1.38) 0.4021$ & $4.22(2.01,8.87) 0.0001$ & 0.0001 \\
\hline Model I & $1.12(0.89,1.41) 0.3255$ & $2.34(1.16,4.72) 0.0173$ & 0.0304 \\
\hline Model I* & $1.12(0.89,1.41) 0.3281$ & $2.32(1.14,4.69) 0.0196$ & 0.0338 \\
\hline Model II & $0.98(0.74,1.31) 0.9038$ & $3.96(1.78,8.82) 0.0007$ & $<0.0001$ \\
\hline Model II* & $1.02(0.76,1.36) 0.8986$ & $3.83(1.68,8.72) 0.0014$ & 0.0004 \\
\hline \multicolumn{4}{|l|}{ Total } \\
\hline Crude & $1.24(1.00,1.54) 0.0496$ & $2.42(1.55,3.80) 0.0001$ & 0.0018 \\
\hline Model I & $1.17(0.94,1.44) 0.1514$ & $1.33(0.87,2.03) 0.1850$ & 0.5459 \\
\hline Model I* & $1.16(0.93,1.43) 0.1809$ & $1.46(0.93,2.30) 0.0976$ & 0.3014 \\
\hline Model II & $1.00(0.76,1.30) 0.9877$ & $2.15(1.32,3.51) 0.0021$ & 0.0006 \\
\hline Model II* & $1.04(0.80,1.36) 0.7621$ & $1.94(1.18,3.16) 0.0085$ & 0.0085 \\
\hline \multicolumn{4}{|c|}{ Model I: Adjusted for age } \\
\hline \multicolumn{4}{|c|}{ Model I*: Adjusted for age and the interaction terms for age } \\
\hline \multicolumn{4}{|c|}{$\begin{array}{l}\text { Model II: Adjusted for age, PS, LDL, HDL, TG, BS, SBP, DBP, BMI, metabolic syndrome, medication to } \\
\text { reduce blood pressure, medication to reduce blood sugar or insulin injection, medication to reduce the } \\
\text { level of cholesterol, drinking habits, and plaque number }\end{array}$} \\
\hline \multicolumn{4}{|c|}{$\begin{array}{l}\text { Model II*: Adjusted for age, PS, LDL, HDL, TG, BS, SBP, DBP, BMI, metabolic syndrome, medication to } \\
\text { reduce blood pressure, medication to reduce blood sugar or insulin injection, medication to reduce the } \\
\text { level of cholesterol, drinking habits, plaque number and the interaction terms for following variables: } \\
\text { age, PS, LDL, HDL, TG, BS, SBP, DBP, BMI, metabolic syndrome, medication to reduce blood pressure, } \\
\text { medication to reduce blood sugar or insulin injection, medication to reduce the level of cholesterol, } \\
\text { drinking habits, plaque number }\end{array}$} \\
\hline
\end{tabular}


In this population-based retrospective cohort study, we found that there was no association of HbA1c with cerebral WMLs in men. Our findings indicate a nonlinear relationship between $\mathrm{HbA} 1 \mathrm{c}$ and cerebral WMLs in women after adjusting for other covariates, for whom the cutoff point was $5.6 \%$. This result suggests a $\mathrm{U}$ shape of the independent association between $\mathrm{HbA1c}$ and cerebral WMLs in women. In addition, we also found that the trend of the effect sizes on the left and right sides of the inflection point was not consistent (left $\mathrm{OR}=0.2195 \% \mathrm{Cl} 0.06,0.69 \mathrm{P}=0.0098$ ); right $\mathrm{OR}=3.595 \% \mathrm{Cl} 1.50,8.15 \mathrm{P}=$ 0.0037). Interaction tests will help us to better understand the trends of HbA1c and cerebral WMLs in different populations. The results of this study found a stronger association between $\mathrm{HbA} 1 \mathrm{c}$ levels and cerebral WMLs in women than in men in the higher HbA1c group.

Individuals with diabetes are at high risk of various complications, mostly vascular-associated complications, such as cardiovascular disease, stroke, neuropathy, nephropathy and retinopathy. However, the risks of complications in individuals with diabetes are different. More recent data have clearly demonstrated that the pathophysiology and excess risk of vascular and nonvascular outcomes of diabetes vary by sex 7,9 . Data suggest that cardiovascular risk factors present a higher burden and greater effect on women with diabetes than on men with diabetes ${ }^{8,25-27}$. However, sex differences in the association between diabetes and cerebral WMLs have not yet been illuminated. Over the last few years, many studies concentrating on the possible determinants of cerebral WMLs have suggested chronic ischemic pathogenesis in the development and progression of WMD. Among the many vascular risk factors possibly implicated in the pathogenesis of cerebral WMLs, type 2 diabetes mellitus has been a strong risk factor. Studies have shown that structural brain abnormalities already occur in prediabetes as well as diabetes ${ }^{19}$. Nearly half of previous studies reported a statistically significant association between diabetes mellitus and cerebral WMLs, while the others reported the opposite ${ }^{15}$. A study by Saczynski et al. showed that participants with type 2 diabetes had a higher percentage of WMLs after adjustment for demographic and cardiovascular risk factors in a sample of 4415 participants ${ }^{28}$. Van Agtmaal et al. suggested that prediabetes and type 2 diabetes were associated with larger white matter hyperintensities ${ }^{19}$. Similar findings were also reported in studies by Espeland M.A. and Ropele $S^{29,30}$. However, there are some other studies that are inconsistent with those above. R. Nick Bryan et al. reported that there was no association of diabetes characteristics with small vessel ischemic disease in the brain in their sample of patients with type 2 diabetes mellitus ${ }^{31}$. A study by Moran et al. showed that type 2 diabetes mellitus was not associated with microbleeds or $\mathrm{WMHs}^{16}$. A large-scale systematic review considered imaging methods with different sensitivities used to study the extent of WMLs, which may contribute to the inconsistency in conclusions on the association between DM and WMLs ${ }^{15}$. We analyzed the reasons why these studies are inconsistent, and we speculate that the reasons for the different results may be due to the following factors: (1) the research populations are different; (2) the different conclusions do not clarify the nonlinear relationship; (3) the different conclusions do not clarify sex differences in the relationship between $\mathrm{HbA} 1 \mathrm{c}$ and cerebral WMLs; and (4) the studies did not take into account the effect of plaque number and carotid plaque score on the HbA1c and cerebral WML 
relationship when adjusting for covariates. However, previous studies have confirmed that these variables are related to $\mathrm{HbA} 1 \mathrm{c}$ or cerebral WMLs ${ }^{32}$.

Our study showed that a higher level of HbA1c has a greater impact on women's risk for WMLs than on men's risk. The inflection point of the $U$ shape on the independent association between $\mathrm{HbA} 1 \mathrm{c}$ and cerebral WMLs was $5.6 \%$. This indicated that more aggressive treatment should be considered in women for cerebral WML prevention and for glycemic targets in Japan. When HbA1c is lower than $5.6 \%$, the level of $\mathrm{HbA} 1 \mathrm{c}$ is negatively associated with cerebral WMLs, which indicates that hypoglycemic conditions may also contribute to the development of cerebral WMLs. The mechanisms that explain the sex difference in the risk of vascular disease associated with diabetes have not been identified. However, this excess risk among women could be due to certain underlying biological differences and health care provided for diabetes and its vascular complications between women and men ${ }^{33}$. Several studies supported that women underwent more pronounced exposure to hazardous metabolic risk factors than men before the onset of type 2 diabetes $^{34-37}$. Among 500,000 individuals in the UK Biobank, the difference in waist circumference and BMI between those with and without diabetes was larger in women than men ${ }^{38}$. Moreover, women have similar levels of $\mathrm{HbA} 1 \mathrm{c}$ but a remarkably higher BMI than men when first diagnosed with diabetes ${ }^{39,40}$. These disadvantageous obesity-associated mechanisms in women were speculated to be partly responsible for the sex difference in the risk of vascular disease associated with diabetes. In contrast to the above conclusions, our study showed a lower BMI in women than in men in the higher HbA1c group. Previous studies showed that women who converted to diabetes showed relatively worse levels of total cholesterol, $\mathrm{HDL}$ cholesterol, triglycerides and DBP at baseline than men. In contrast, women with higher levels of HbA1c had relatively better levels of $L H, T G$ and DBP than men in the Japanese population. In addition to biological differences between men and women, disparities in health care may in part explain sex differences in diabetes-related vascular complications. Previous studies showed that secondary prevention in risk factor management was generally worse in women than in men ${ }^{41}$. Our study showed a similar outcome. Women with higher levels of $\mathrm{HbA} 1 \mathrm{c}$ are less likely to take medicine for BP and blood sugar than men. Sex differences in biological factors, such as both the use and provision of health care, could contribute to women's higher relative risk of diabetic vascular complications. There were still significant sex differences in the association between $\mathrm{HbA} 1 \mathrm{c}$ and cerebral WMLs after adjusting for associated covariates.

The clinical value of this study is as follows: (1) To the best of our knowledge, this is the first study to observe the independent nonlinear association between HbA1c and cerebral WMLs in women; (2) to the best of our knowledge, this is the first study to observe sex differences in the association between HbA1c and cerebral WMLs in women and men; and (3) the findings from this study should contribute to future research on the establishment of diagnostic or predictive models of cerebral WMLs.

Our study has some strengths. (1) We performed a large population-based analysis of the general population; (2) we address the nonlinearity in the present study and further explore this; (3) as this is an observational study, it was susceptible to various confounding variables. We used strict statistical 
adjustments to minimize residual confounding; and (4) the effect modifier factor analysis improved the use of the data and revealed interactions in different subgroups in this study.

Several possible limitations of the present study should be considered: (1) This was a cross-sectional study. Thus, we could not exclude a causal relationship from the findings of this study. (2) In this study, our research subjects were members of the general population attending a medical screening center in Japan. Therefore, there is a certain deficiency in the universality and extrapolation of research. (3) In this study, our research subjects were mainly prediabetic individuals. Therefore, if the scope of the population is expanded and the diabetes sample size is increased, the results obtained will be more persuasive. Despite these potential limitations, this analysis adds to the body of knowledge regarding the effect of $\mathrm{HbA} 1 \mathrm{c}$ on the risk of WMLs by quantifying the dramatic impact of $\mathrm{HbA} 1 \mathrm{c}$ in women after accounting for other known WML risk factors.

\section{Perspectives And Significance}

This study highlights sex differences in the association between cerebral WMLs and HbA1c. Women had a much higher odds ratio of cerebral WMLs associated with HbA1c than men in higher HbA1c group.

These findings suggest that more careful glycemic control may be needed in women with hyperglycemia to prevent cerebral WMLs. Sex differences should be taken into consideration in assessing the association between HbA1c and cerebral WMLs.

\section{Methods}

\section{Data source}

The secondary data were obtained from the DATADRYAD database (www.Datadryad.org). Users are permitted to download raw data freely from this website. According to the Dryad Terms of Service, we cited the Dryad data package in the present study. (Dryad data package: Shinkawa, Yuya et al. (2019), data from: Mathematical modeling for the prediction of cerebral WMLs based on clinical examination data, Dryad, Dataset, https://doi.org/10.5061/dryad.73bh2q8). The target independent variable was $\mathrm{HbA1c}$ level obtained at baseline, and the outcome variable was cerebral WMLs. Covariates involved in this study included PS (carotid plaque score), systolic blood pressure (SBP), diastolic blood pressure (DBP), body mass index (BMI), LDL cholesterol (LDL), HDL cholesterol (HDL), LH ratio (quotient of LDL and $\mathrm{HDL}$ ), triglyceride (TG), blood glucose level (BS), plaque number (n-plaque), age, sex, smoking habit (Smoke), metabolic syndrome (Met-syn), medication to reduce blood pressure (Med-BP), medication to reduce blood sugar or insulin injection (Med-sugar), medication to reduce the level of cholesterol (Medcho), amount of drinking per day (Drink-V), and drinking habit.

\section{Study population}

Shinkawa Yuya et al. completed the entire study. The specific details are described in the original report by Shinkawa Yuya ${ }^{24}$. Participant data were nonselectively and consecutively collected from subjects who 
underwent brain MRI and blood tests during the brain dock course of a comprehensive medical checkup some time between April 1, 2016, and October 31, 2017, at Shin Takeo Hospital. A total of 1904 participants, including 988 men and 916 women, were involved in this study. The data in the database were anonymous for the purpose of protecting participant privacy. Data are stored in an electronic data acquisition system. Participants' informed consent was not required in this study because of the nature of the retrospective cohort study. This study was approved by the ethical review committee of Shin Takeo Hospital.

Ethical approval. This analysis is based on summary statistics obtained from previously published analyses and therefore we have not sought additional ethical approval. All methods were performed in accordance with the relevant guidelines and regulations. Due to the retrospective nature of the study design and anonymous data collection, written informed consent was waived by the ethical review committee of Shin Takeo Hospital.

\section{Variables}

$\mathrm{HbA1c}$ was measured at baseline and recorded as a continuous variable. The blood and biochemical indexes were detected by the laboratory test systems C8000 (Canon Medical Systems Corporation, Tochigi, Japan) and Acute (Canon Medical Systems Corporation, Tochigi, Japan), respectively. HbA1c was measured with an automated glycohemoglobin analyzer HA8181 (Arkray Inc., Kyoto, Japan).

The outcome variable (dichotomous variable) was determined according to published guidelines and studies. Head magnetic resonance imaging (MRI) scans were acquired on MAGNETOM Symphony (Siemens Healthineers Japan, Tokyo, Japan) and MAGNETOM ESSENZA (Siemens Healthineers Japan, Tokyo, Japan) scanners. The detailed process of definition of cerebral WMLs is described as follows: there are periventricular or deep white matter lesions on FLAIR sequence of MRI (dichotomous variable: 1 $=$ presence of cerebral white matter lesions on MRI; $0=$ absence of cerebral white matter lesions on MRI).

The variables in this study can be divided into three types: (1) demographic data; (2) variables that can affect $\mathrm{HbA} 1 \mathrm{c}$ or cerebral WMLs reported by previous literature; and (3) variables based on our clinical experiences. We selected these covariates on the basis of their association with the outcomes or a change in effect estimate of more than $10 \%$. Therefore, the following variables were used to construct the fully adjusted model: (1) continuous variables: HDL, LDL, TG, SBP, DBP, BMI, PS, and BS (obtained at baseline); (2) categorical variables: age, sex, metabolic syndrome, medication to reduce blood pressure, medication to reduce blood sugar or insulin injection, medication to reduce the level of cholesterol, drinking habit (every day, sometimes, or rarely drink (cannot drink)) (obtained at baseline) and plaque number. Binary variables take a value of 0 or 1 to indicate the absence or presence of some categorical effect, respectively, e.g., sex: $X=0$ for men and $X=1$ for women; medication to reduce blood pressure: $X=$ 0 for "No" and $X=1$ for "Yes"; medication to reduce blood sugar or insulin injection: $X=0$ for "No" and $X=$ 1 for "Yes"; medication to reduce blood pressure: $X=0$ for "No" and $X=1$ for "Yes". For the purpose of fully adjusting variables, we converted age from a categorical variable to a continuous variable. 


\section{Statistical analysis}

Quantitative continuous variables are presented as the mean \pm standard deviation (normal distribution), and categorical variables are presented as the number and percentage. We used $\chi 2$ (categorical variables) or Student's T test (normal distribution) to test for differences among men and women in different HbA1c groups (clinical cut point). The data analysis process of this study was based on three criteria: (1) what is the relationship between HbA1c and cerebral WMLs (linear or nonlinear) in men and women? (2) which factors modify or interfere with the relationship between HbA1c and cerebral WMLs in men and women? and (3) after adjustment for the interfering factors or after the stratified analysis, what is the true relationship between $\mathrm{HbA} 1 \mathrm{c}$ and cerebral WMLs in men and women? Therefore, data analysis can be summarized in three steps. Step 1: Univariate and multivariate binary logistic regression were employed. We constructed two models: model 1, minimally adjusted model, adjusted only for age; model 2 , fully adjusted model, adjusted for those covariates as just described. Step 2: To address the nonlinearity of $\mathrm{HbA} 1 \mathrm{c}$ and cerebral WMLs, a generalized additive model and smooth curve fitting (penalized spline method) stratified by sex were conducted. If there is a nonlinear relationship, a recursive algorithm is used to calculate the inflection point, and then two-piecewise binary logistic regression on both sides of the inflection point is constructed. The log likelihood ratio test was used to determine the most suitable model for fitting the association between the independent variable and outcome variable. Step 3: In view of the difference in association between HbA1c and cerebral WMLs in men and women reflected by smooth curve fitting, we performed an interaction test between $\mathrm{HbA} 1 \mathrm{c}$ and sex in different $\mathrm{HbA1c}$ groups. All analyses were performed with the statistical software packages $\mathrm{R}$ (http://www.Rproject.org, The R Foundation) and Empower Stats (http://www.empowerstats.com, X\&Y Solutions, Inc, Boston, MA). P values less than 0.05 (two-sided) were considered statistically significant.

\section{Abbreviations}

LDL: low-density lipoprotein; HDL: high-density lipoprotein; LH: quotient of LDL and HDL; TG: triglyceride; BS: blood glucose level; SBP: systolic blood pressure; DBP: diastolic blood pressure; BMI: body mass index; PS: carotid plaque score; Met-syn: metabolic syndrome; Med-bp: medication to reduce blood pressure; Med-sugar: medication to reduce blood sugar or insulin injection; Med-cho: medication to reduce the level of cholesterol; Drink-V: amount of drinking per day; WMLs: white matter lesions

\section{Declarations}

\section{Acknowledgment}

The author is very grateful to the data providers of the study. They completed the entire study. They are Shinkawa Yuya, Takashi Yoshida, Yohei Onaka, Makoto Ichinose, Kazuo Ishii. The authors also thank Chang-zhong Chen and Xing-Lin Chen of Yi-er college.

\section{Author contributions statement}


$\mathrm{HL}$ and JY contributed to the drafting of the manuscript, and analysis and interpretation of the data. SG contributed to the conception and critical revision of the manuscript, analysis and interpretation of the data and approved the final version of the submitted manuscript. Both authors read and approved the final manuscript.

\section{Additional information}

Competing interests: The authors declare that they have no competing interests.

Consent for publication: Not applicable.

Availability of data and materials: All data can be downloaded from DATADRYAD database (www.Datadryad.org).

Funding: We receive no funding support.

\section{References}

1 Wild, S., Roglic, G., Green, A., Sicree, R. \& King, H. Global prevalence of diabetes: estimates for the year 2000 and projections for 2030. Diabetes Care27, 1047-1053, doi:10.2337/diacare.27.5.1047 (2004).

2 Zimmet, P., Alberti, K. G. \& Shaw, J. Global and societal implications of the diabetes epidemic. Nature414, 782-787, doi:10.1038/414782a (2001).

3 Sorensen, B. M. et al. Prediabetes and Type 2 Diabetes Are Associated With Generalized Microvascular Dysfunction: The Maastricht Study. Circulation134, 1339-1352, doi:10.1161/CIRCULATIONAHA.116.023446 (2016).

4 Marseglia, A. et al. Prediabetes and diabetes accelerate cognitive decline and predict microvascular lesions: A population-based cohort study. Alzheimers Dement15, 25-33, doi:10.1016/j.jalz.2018.06.3060 (2019).

5 Li, C., Ford, E. S., Zhao, G. \& Mokdad, A. H. Prevalence of pre-diabetes and its association with clustering of cardiometabolic risk factors and hyperinsulinemia among U.S. adolescents: National Health and Nutrition Examination Survey 2005-2006. Diabetes Care32, 342-347, doi:10.2337/dc08-1128 (2009).

6 Ziegler, D. et al. Prevalence of polyneuropathy in pre-diabetes and diabetes is associated with abdominal obesity and macroangiopathy: the MONICA/KORA Augsburg Surveys S2 and S3. Diabetes Care31, 464-469, doi:10.2337/dc07-1796 (2008).

7 Alfredsson, J. et al. Sex differences in management and outcomes of patients with type 2 diabetes and cardiovascular disease: A report from TECOS. Diabetes Obes Metab20, 2379-2388, doi:10.1111/dom.13377 (2018). 
8 Natarajan, S., Liao, Y., Cao, G., Lipsitz, S. R. \& McGee, D. L. Sex differences in risk for coronary heart disease mortality associated with diabetes and established coronary heart disease. Arch Intern Med163, 1735-1740, doi:10.1001/archinte.163.14.1735 (2003).

9 Faerch, K., Borch-Johnsen, K., Vaag, A., Jorgensen, T. \& Witte, D. R. Sex differences in glucose levels: a consequence of physiology or methodological convenience? The Inter99 study. Diabetologia53, 858-865, doi:10.1007/s00125-010-1673-4 (2010).

10 Lind, M., Oden, A., Fahlen, M. \& Eliasson, B. The true value of HbA1c as a predictor of diabetic complications: simulations of HbA1c variables. PLoS One4, e4412, doi:10.1371/journal.pone.0004412 (2009).

11 Matuleviciene-Anangen, V. et al. Glycaemic control and excess risk of major coronary events in persons with type 1 diabetes. Heart103, 1687-1695, doi:10.1136/heartjnl-2016-311050 (2017).

12 Wang, S. Y., Andrews, C. A., Herman, W. H., Gardner, T. W. \& Stein, J. D. Incidence and Risk Factors for Developing Diabetic Retinopathy among Youths with Type 1 or Type 2 Diabetes throughout the United States. Ophthalmology124, 424-430, doi:10.1016/j.ophtha.2016.10.031 (2017).

13 Wardlaw, J. M. et al. Neuroimaging standards for research into small vessel disease and its contribution to ageing and neurodegeneration. Lancet Neuro/12, 822-838, doi:10.1016/S14744422(13)70124-8 (2013).

14 Wardlaw, J. M., Smith, C. \& Dichgans, M. Mechanisms of sporadic cerebral small vessel disease: insights from neuroimaging. Lancet Neuro/12, 483-497, doi:10.1016/S1474-4422(13)70060-7 (2013).

15 Del Bene, A. et al. Is type 2 diabetes related to leukoaraiosis? an updated review. Acta Neurol Scand132, 147-155, doi:10.1111/ane.12398 (2015).

16 Moran, C. et al. Brain atrophy in type 2 diabetes: regional distribution and influence on cognition. Diabetes Care36, 4036-4042, doi:10.2337/dc13-0143 (2013).

17 Putaala, J. et al. Silent brain infarcts and leukoaraiosis in young adults with first-ever ischemic stroke. Neurology72, 1823-1829, doi:10.1212/WNL.0b013e3181a711df (2009).

18 Sanahuja, J. et al. Increased Burden of Cerebral Small Vessel Disease in Patients With Type 2 Diabetes and Retinopathy. Diabetes Care39, 1614-1620, doi:10.2337/dc15-2671 (2016).

19 van Agtmaal, M. J. M. et al. Prediabetes Is Associated With Structural Brain Abnormalities: The Maastricht Study. Diabetes Care41, 2535-2543, doi:10.2337/dc18-1132 (2018).

20 Manschot, S. M. et al. Brain magnetic resonance imaging correlates of impaired cognition in patients with type 2 diabetes. Diabetes55, 1106-1113, doi:10.2337/diabetes.55.04.06.db05-1323 (2006). 
21 Murray, A. D. et al. Brain white matter hyperintensities: relative importance of vascular risk factors in nondemented elderly people. Radiology237, 251-257, doi:10.1148/radiol.2371041496 (2005).

22 Rozanski, M. et al. Elevated levels of hemoglobin A1c are associated with cerebral white matter disease in patients with stroke. Stroke45, 1007-1011, doi:10.1161/STROKEAHA.114.004740 (2014).

23 Heo, S. H., Lee, S. H., Kim, B. J., Kang, B. S. \& Yoon, B. W. Does glycated hemoglobin have clinical significance in ischemic stroke patients? Clin Neurol Neurosurg112, 98-102, doi:10.1016/j.clineuro.2009.08.024 (2010).

24 Shinkawa, Y., Yoshida, T., Onaka, Y., Ichinose, M. \& Ishii, K. Mathematical modeling for the prediction of cerebral white matter lesions based on clinical examination data. PLoS One14, e0215142, doi:10.1371/journal.pone.0215142 (2019).

$25 \mathrm{Hu}, \mathrm{G}$. \& Group, D. S. Gender difference in all-cause and cardiovascular mortality related to hyperglycaemia and newly-diagnosed diabetes. Diabetologia46, 608-617, doi:10.1007/s00125-003-10966 (2003).

26 Barrett-Connor, E. L., Cohn, B. A., Wingard, D. L. \& Edelstein, S. L. Why is diabetes mellitus a stronger risk factor for fatal ischemic heart disease in women than in men? The Rancho Bernardo Study. JAMA265, 627-631 (1991).

27 Jousilahti, P., Vartiainen, E., Tuomilehto, J. \& Puska, P. Sex, age, cardiovascular risk factors, and coronary heart disease: a prospective follow-up study of 14786 middle-aged men and women in Finland. Circulation99, 1165-1172, doi:10.1161/01.cir.99.9.1165 (1999).

28 Saczynski, J. S. et al. Glycemic status and brain injury in older individuals: the age gene/environment susceptibility-Reykjavik study. Diabetes Care32, 1608-1613, doi:10.2337/dc08-2300 (2009).

29 Espeland, M. A. et al. Influence of type 2 diabetes on brain volumes and changes in brain volumes: results from the Women's Health Initiative Magnetic Resonance Imaging studies. Diabetes Care36, 90-97, doi:10.2337/dc12-0555 (2013).

30 Ropele, S. et al. The impact of sex and vascular risk factors on brain tissue changes with aging: magnetization transfer imaging results of the Austrian stroke prevention study. AJNR Am J Neuroradio/31, 1297-1301, doi:10.3174/ajnr.A2042 (2010).

31 Bryan, R. N. et al. Effect of diabetes on brain structure: the action to control cardiovascular risk in diabetes MR imaging baseline data. Radiology272, 210-216, doi:10.1148/radiol.14131494 (2014).

$32 \mathrm{Nam}, \mathrm{K}$. W. et al. Cerebral white matter hyperintensity is associated with intracranial atherosclerosis in a healthy population. Atherosclerosis265, 179-183, doi:10.1016/j.atherosclerosis.2017.09.010 (2017). 
33 de Ritter, R. et al. Sex differences in the risk of vascular disease associated with diabetes. Biol Sex Differ11, 1, doi:10.1186/s13293-019-0277-z (2020).

34 Peters, S. A., Huxley, R. R. \& Woodward, M. Diabetes as risk factor for incident coronary heart disease in women compared with men: a systematic review and meta-analysis of 64 cohorts including 858,507 individuals and 28,203 coronary events. Diabetologia57, 1542-1551, doi:10.1007/s00125-014-3260-6 (2014).

35 Juutilainen, A. et al. Gender difference in the impact of type 2 diabetes on coronary heart disease risk. Diabetes Care27, 2898-2904, doi:10.2337/diacare.27.12.2898 (2004).

36 Woodward, M., Peters, S. A. \& Huxley, R. R. Diabetes and the female disadvantage. Womens Health (Lond)11, 833-839, doi:10.2217/whe.15.67 (2015).

37 Peters, S. A., Huxley, R. R., Sattar, N. \& Woodward, M. Sex Differences in the Excess Risk of Cardiovascular Diseases Associated with Type 2 Diabetes: Potential Explanations and Clinical Implications. Curr Cardiovasc Risk Rep9, 36, doi:10.1007/s12170-015-0462-5 (2015).

38 Peters, S. A., Huxley, R. R. \& Woodward, M. Sex differences in body anthropometry and composition in individuals with and without diabetes in the UK Biobank. BMJ Open6, e010007, doi:10.1136/bmjopen2015-010007 (2016).

39 Paul, S., Thomas, G., Majeed, A., Khunti, K. \& Klein, K. Women develop type 2 diabetes at a higher body mass index than men. Diabetologia55, 1556-1557, doi:10.1007/s00125-012-2496-2 (2012).

40 Logue, J. et al. Do men develop type 2 diabetes at lower body mass indices than women? Diabetologia54, 3003-3006, doi:10.1007/s00125-011-2313-3 (2011).

41 Zhao, M. et al. Sex differences in risk factor management of coronary heart disease across three regions. Heart103, 1587-1594, doi:10.1136/heartjnl-2017-311429 (2017).

\section{Figures}



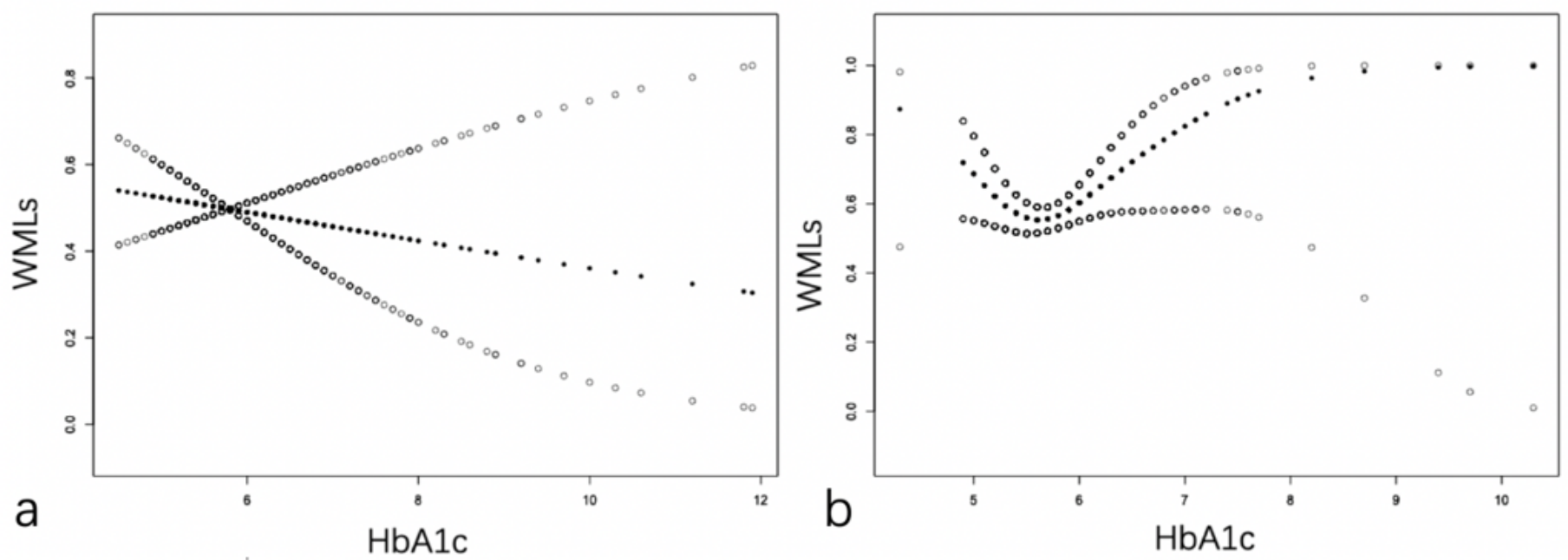

\section{Figure 1}

Smooth curve fitting of HbA1c and cerebral WMLs for men and women. A linear relationship between them was detected in men after adjusting for age, HDL, LDL, TG, DBP, SBP, BMI, BS, PS, drinking habit, metabolic syndrome, medication to reduce blood pressure, medication to reduce blood sugar or insulin injection, medication to reduce cholesterol, and n-plaque (a). A nonlinear relationship between them was detected in women after adjusting for age, HDL, LDL, TG, DBP, SBP, BMI, BS, PS, drinking habit, metabolic syndrome, medication to reduce blood pressure, medication to reduce blood sugar or insulin injection, medication to reduce cholesterol levels, and n-plaque (b). 